\title{
THREE DIMENSIONAL FINITE ELEMENT ANALYSIS OF THE STRESSES INDUCED IN BONE SURROUNDING SPLINTED \& UN-SPLINTED IMPLANTS IN IMPLANT RETAINED MAXILLARY OBTURATORS FOR COMPLETELY EDENTULOUS MAXILLECTOMY PATIENTS
}

\author{
Mohamed Abdel Hakim Abdel Aal*
}

\begin{abstract}
Purpose: The present study is an in-vitro study conducted to evaluate the stress distribution pattern in bone surrounding splinted \& non-splinted implants in implant- retained maxillary obturators with Ball \& Hader bar attachment systems using three dimensional FEA.
\end{abstract}

Materials \& Methods: CT scan was made for a completely edentulous patient with class I maxillary defect. The CT scan file was sent to a personal computer with Materialize Mimics 10.01 program (Materialize, interactive medical image (Materialize Leuven, Belgium). Mimics was used to modify the CT scan of the maxilla to construct 3-D model with Solid Works, Concord, Massachusetts, USA) for 3-D FEA. All components of the models were simulated \& constructed after that and they were superimposed until construction of the model of the maxillary obturator. Three implants were inserted in the alveolar bone on the intact side, one adjacent to the defect, one at the canine area and one at the $2^{\text {nd }}$ premolar area. Ball attachments \& Hader bar \& clips attachment systems were simulated according to the manufacturer structural configurations. A static load of $100 \mathrm{~N}$ load was applied vertically \& obliquely on the defect side. ANSYS program (Canonsburg, PA, USA) was utilized to solve the problems. Von Misses stresses in bone surrounding implants were evaluated and compared in the two study models.

Results: The highest Von Misses stresses were found in cortical bony layers around the implant adjacent to the defect $\&$ the least stresses at the area of $3^{\text {rd }}$ implant. Ball attachment retained implant obturators had recorded the least Von Misses stresses (40.762 Mpa, 26.175 Mpa \& 10.62) \& (41.484 Mpa, 28.656 Mpa \& $15.585 \mathrm{Mpa})$ around the $1^{\text {st }}, 2^{\text {nd }} \& 3^{\text {rd }}$ implants respectively. Meanwhile, the Hader bar \& clip attachment systems (43.526 Mpa, 29.17 Mpa \& 8.6 Mpa) and (53.802 Mpa, $30.5 \mathrm{Mpa} \& 9.6 \mathrm{Mpa})$ under vertical \& oblique load application around the $1^{\text {st }}, 2^{\text {nd }} \& 3^{\text {rd }}$ implants respectively. All models had shown the highest stresses on oblique load application on the defect side.

* Lecturer of Removable Prosthodontics, Faculty of Oral and Dental Medicine, Beni-Suef University 


\section{Conclusions:}

Within the limitations of this study it may be concluded that:

- Ball attachment system may induce the least stresses onto implant/ bone interface.

-Bar retained maxillary obturators result in higher stress concentration around the implants underneath.

- Hader bar \& clip attachment may allow better stress distribution in implant retained maxillary obturators than other Bar systems.

The load direction has more important role than the attachment type in stress distribution pattern in implant retained maxillary obturators.

KEYWORDS: Maxillary obturators, implants; attachments, finite element analysis.

\section{INTRODUCTION}

Rehabilitation of the maxillary defects is important to restore the oral functions, facial contour and improve the patient's quality of life. Obturator prosthesis is the preferred method for rehabilitation for most maxillectomy patients. ${ }^{(1)}$

Prosthetic rehabilitation of completely edentulous maxillectomy patients is considered a real challenge for the prosthodontist. The obturator retention, stability and support are greatly compromised due to reduced maxillary bony tissues after the tumor resection. The retention problem may affect the treatment outcome \& consequently affecting the patient's quality of life. ${ }^{(2,3)}$

Many techniques had been developed to overcome the problem of retention \& stability of the maxillary obturator such as maximum area coverage, the use of precision attachments and the use of retention aids as springs and adhesives ${ }^{(4)}$

However the introduction of dental implants had provided a dramatic effect on the retention \& stability of the obturator prosthesis especially in completely edentulous maxillectomy patients.

Implants may be placed \& distributed in the area of remaining pre-maxilla as it provides sufficient bone quantity and quality required for implant insertion and osseointegration. ${ }^{(5)}$
Moreover, implants may be inserted in the defect side and intact sides of the maxillary arch. The number of implants and their location is determined by the nature of the defect and the available bony sites ${ }^{(6)}$

Previous studies had proved that the survival rate of the implants may approach $96 \%$ or more in implant retained maxillary obturators. ${ }^{(7)}$

Stud attachments as ball, locator, ERA attachments were utilized to improve the obturator retention. However, O-ring and ERA attachments were preferred by some clinicians due to the reduced vertical height allowing their simple use even in reduced inter-arch space. ${ }^{\left({ }^{(8)}\right.}$

Bar attachment had been used to splint implants supporting obturators in completely edentulous maxillectomy patients without any reported complications during the follow-up period. However, the implants were subjected to high stress levels that may affect the adjacent bone and result in bone resorption \& implant failure. ${ }^{(9)}$

Parel et al., 2001 suggested that cross-arch stabilization with a rigid splint framework with sufficient antreo-posterior spread is essential for effective axial loading of the implant. ${ }^{(10)}$

Parel et al., 2001 added that proper positioning \& proper alignment of the zygomatic implants \& standard implants will enhance the splinting effect 
of the bar attachment assembly in implant retained maxillary obturators. ${ }^{(10)}$

Finite element analysis ( FEA) is considered a useful tool to predict the stress distribution patterns in the implants \& implant /bone interface. ${ }^{(11)}$

Masticatory forces result in vertical and transverse load components. These loads may induce axial stresses and bending moments leading to stress gradients in the implant $\&$ bone.

Due to the complex geometry of the multiple components in implant/abutment / bone system; FEA has been considered the most suitable tool to study the stresses affecting dental implants from the biomechanical point of view. ${ }^{(12)}$

Consequently, this study was conducted to evaluate the stress distribution patterns in nonsplinted \& splinted implant retained maxillary obturators in completely edentulous patients with the aid of three dimensional finite element analysis.

\section{MATERIALS \& METHODS}

Two models of implant retained obturators were constructed for 3-D stress analysis as follows:

\section{Modeling of the Maxillary Arch:}

Computerized scanning of completely edentulous maxillary arch with Class I defect (Aramany classification) of a female patient was made. A three-dimensional (3D), finite element, solid model of the human maxilla was made based on CT data.

The CT file was then exported to a personal computer having Materialize Mimics 10.01 program (Materialize, interactive medical image control system, (Materialize Leuven, Belgium) to generate a 3D finite element model of the maxilla with 1.0mm slice thickness

Mimics Software package was utilized to view the maxillary arch curvature to modify the CT scan of the maxilla and to obtain multiple cross sections of maxillary arch to form the 3-D model with solid works 2018 software (Solid Works Corporation, Concord, Massachusetts, USA) for finite element analysis.

The maxilla was represented as a combination of cortical \& cancellous bone. The implant diameter \& length were determined according to bone height \& width at the intended implant positions.

\section{Modeling of Implants:}

The implant used in this study was Legacy, Implant Direct LLC, Malibu Hills, CA 91301USA), $3.7 \mathrm{~mm}$ in width and $10 \mathrm{~mm}$ in length.

The implant was modeled according to its specific dimensions as given by the manufacturer. Three implants were inserted as follows: One implant adjacent to the defect, in the canine-premolar area $\&$ one implant in the area of second premolar, 1 $\mathrm{mm}$ bone thickness was maintained around each implant \& implants were kept $1 \mathrm{~mm}$ away from the maxillary sinus floor. Measurements of the cortical \& cancellous bone were recorded with Mimics software \& transferred as STL file to Geomagic Design $X$, to make the reverse engineering by converting the 3D Image obtained from the Mimics files to solid bodies.

\section{Modeling of Attachment:}

Two types of attachments were used (Ball attachment, Hader Bar \& clip attachment systems). Attachments were simulated according the manufacturer dimensions.

The solid bodies of each component of each model were imported to Solid works 2018 for the assembling procedures, superimposition and Boolean subtraction to avoid any interference among different components of the geometric models.

\section{Modeling of the Obturator:}

Teeth positions were determined according to the average teeth width. Cut sections were made at each tooth site wherever the cortical \& cancellous bony layers surrounding each tooth were identified 
with the "Re-slicing "feature in the Mimics software program. The artificial teeth width \& height were saved as STL file \& sent to Geomagic Design- X to make reverse engineering according to the artificial teeth anatomy Fig (1). The obturator base was designed with the Exocad software to fit onto the defective area, and then transferred as STL file to Geomagic Design X, to proceed with the reverse engineering phase.

A hollow obturator was simulated as shown in Fig (2). Holes were engraved into the fitting surface of the obturator base to allow for fitting of the implant \& corresponding attachments.

After completing the phase of reverse engineering; the models of all components were transferred

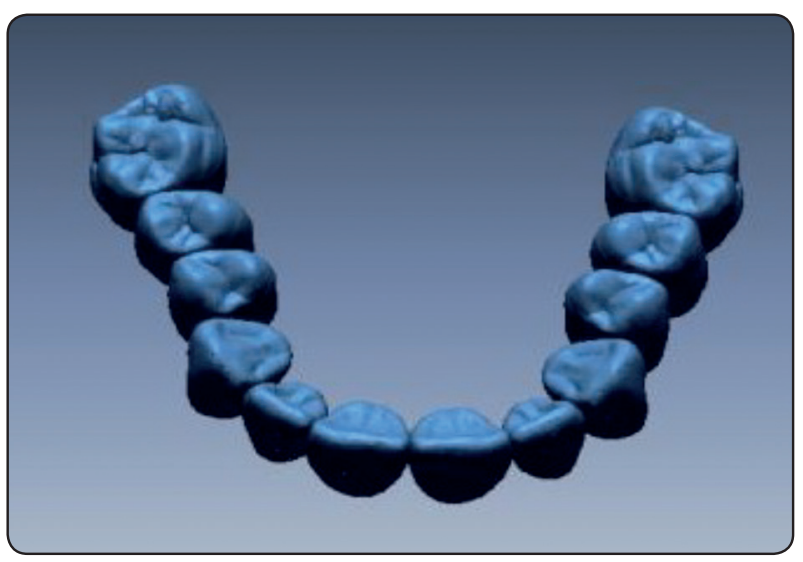

Fig. (1): Virtual set-up of artificial teeth

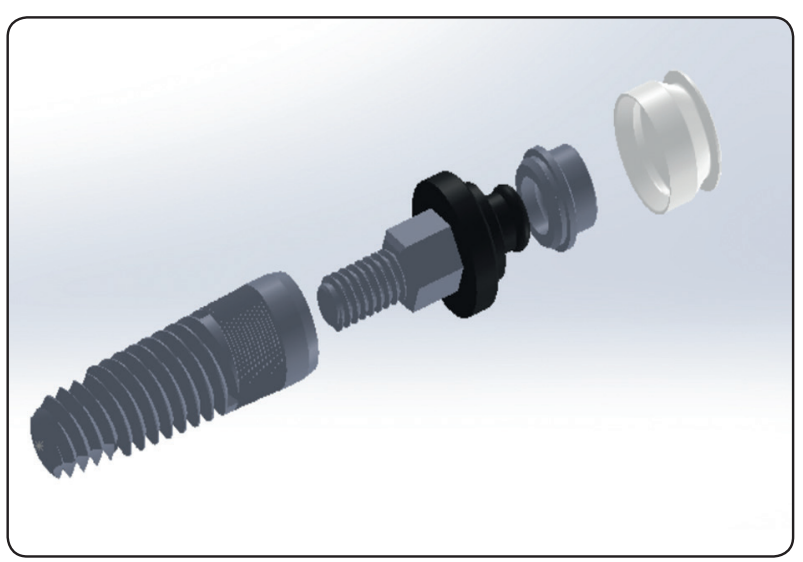

Fig. (3) Model I: Geometric Model of implant \& Ball attachment system to Solid works 2018. All the components of the models were assembled together using the "mating" feature to create geometrical relationships between different model components to fit together. The bone, mucosa, implants, denture base and the different attachment systems were assembled building-up of the two studied models. Fig (5). Boolean subtraction operations were utilized to create the spaces for the cancellous bone, implants, and soft tissues.

Model- I: Ball attachment implant retained obturator (Ball abutment with collar height $1.6 \mathrm{~mm}$, Zimmer dental, USA) Fig(3).

Model- II: Hader Bar \& clips implant retained maxillary obturator Fig (4).

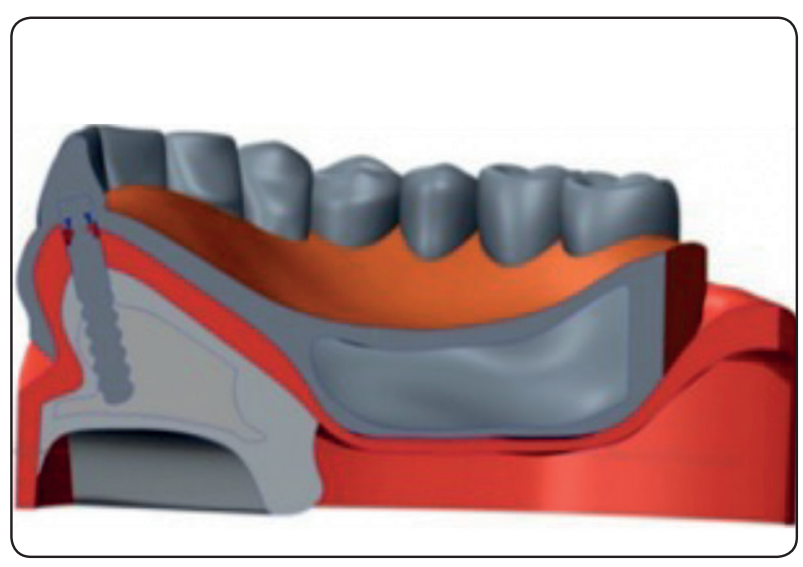

Fig. (2): Geometric Model of implant Retained hollow obturator

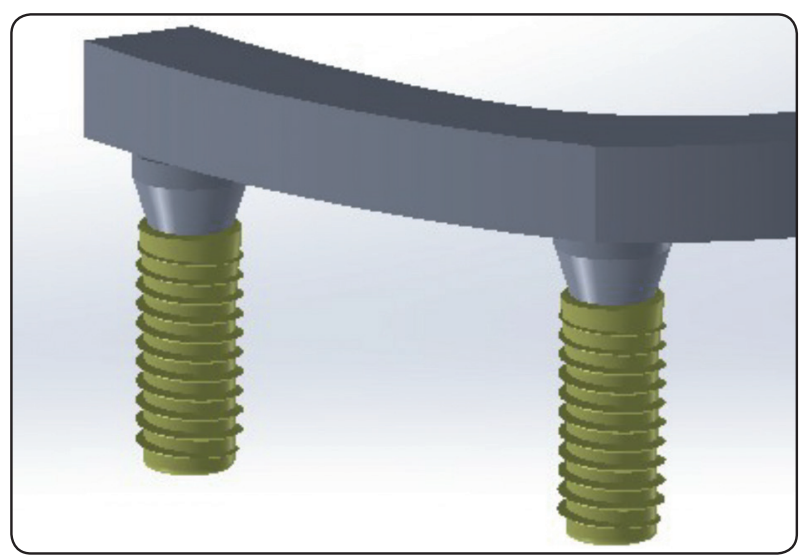

Fig. (4) Model II Geometric model of Implant \& Bar attachment system 


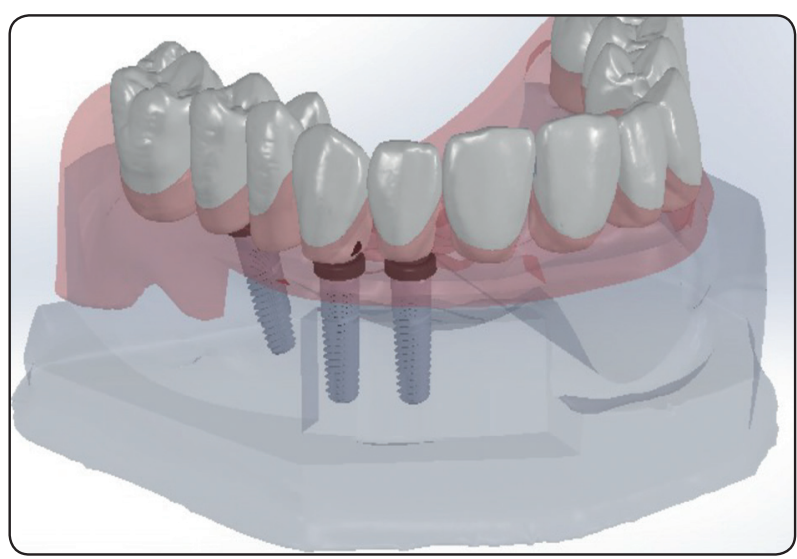

Fig. (5) The complete geometric model of three implant retained obturator

\section{Preparing Finite Element Mesh}

Three-dimensional finite element model of the geometric models were generated using ANSYS's Pre-Processor. Meshing was made with greater number of elements in the areas of expected higher stress distribution at implant bone interface. Fig (6) \& Table (1)

TABLE (1) Number of elements \& nodes in studied models

\begin{tabular}{|c|c|c|}
\hline Model & Number of elements & Number of nodes \\
\hline Model- I & 9752703 & 12587121 \\
\hline Model-II & 13942432 & 12020153 \\
\hline
\end{tabular}

\section{Material properties}

All materials \& tissues used in this study were assumed to be linearly elastic, homogenous, and isotropic ${ }^{(13)}$. The corresponding properties such as Young's modulus and Poisson's ratio of cortical bone, implant, and the bar attachment with stiffener were determined according to literature survey ${ }^{(14)}$. The models with assigned material properties shown in Table (2).

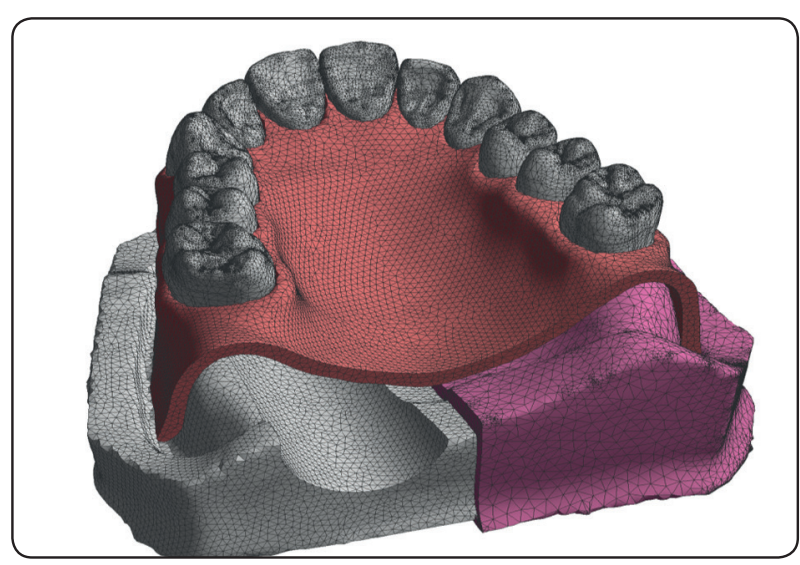

Fig (6) Meshing of the geometric model

TABLE (2): Material properties assigned to the model

\begin{tabular}{|c|c|c|}
\hline & $\begin{array}{c}\text { Young's modulus } \\
(\boldsymbol{M P a})\end{array}$ & Poison's ratio \\
\hline Implant & 103400 & 0.35 \\
\hline Interface & 54450 & 0.325 \\
\hline Nylon Cap & 5.000 & 0.450 \\
\hline Cancellous bone & 5500 & 0.3 \\
\hline Cortical bone & 28500 & 0.3 \\
\hline
\end{tabular}

\section{Defining contacts and gaps between components:}

All components were constructed to ensure $100 \%$ contact along their interfaces. A bonded contact means that the objects are displaced as one unit on load application and the two contacting bodies can't be separated. The exception was the contact between the obturator fitting surface and the mucosa underneath.

\section{Load Application:}

$100 \mathrm{~N}$ was applied vertically \& $45^{\circ}$ oblique applied on the areas of Mxillary $1^{\text {st }} \& 2^{\text {nd }}$ premolars $\& 1^{\text {st }}$ molar on the area of maxillary defect ${ }^{(15)}$ 
The vertical load $(100 \mathrm{~N})$ was applied onto the artificial teeth on the defect side Fig (7).

The oblique load $(100 \mathrm{~N})$ was applied in 45 degrees to the palatal inclines of the artificial teeth on the defect side Fig (7).

The applied load was distributed over the artificial teeth as $(50 \mathrm{~N}$ on the first molar, $20 \mathrm{~N}$ on premolar area $\& 10 \mathrm{~N}$ on the canine).

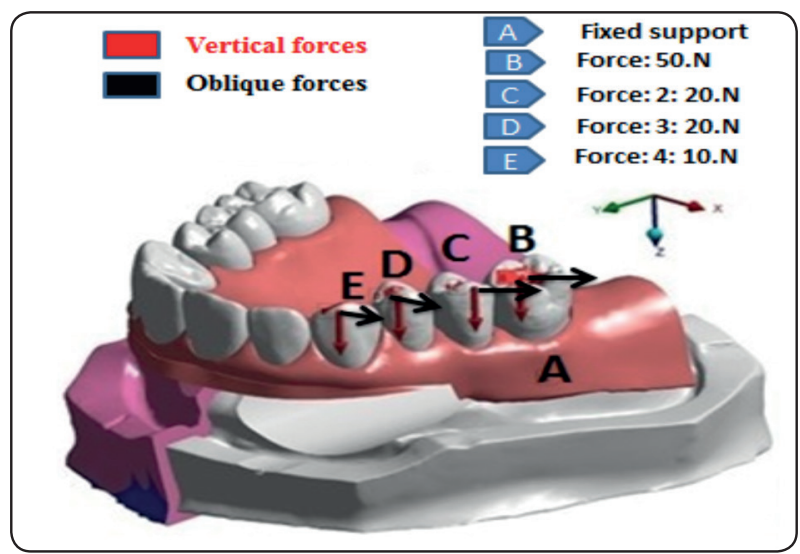

Fig. (7) $100 \mathrm{~N}$ load applied \& distributed verically on artificial teeth on the defect side \& applied obliquely on the buccal inclines of artifical teeth.

\section{RESULTS}

\section{Results of 3D-FEA stress analysis:}

The results of each loading condition applied on each model were collected from the output of ANSYS program Canonsburg, PA, USA). Von Misses' equivalent stresses (S.equiv.) were selected as they are most commonly reported in FEA studies to summarize the overall stress state at a point. Consequently, the critical areas of highest stresses can be easily determined in the studied model. ${ }^{(16)}$

The stress distribution pattern is presented with different color-coding. Red is considered the highest followed by orange, yellow light green, green, light blue, blue, and dark blue colors representing the stresses in descending order.

With these different colors the stress distribution pattern may be analyzed in the studied models.

\section{Results of Model (I): Implant retained maxillary obturator with Ball attachment system:}

Figure $(8 \& 9)$ are showing that the highest stresses could be detected at the palatal cortical plates surrounding the $1^{\text {st }}$ implant adjacent to the maxillary defect, followed by the $2^{\text {nd }} \&$ the $3^{\text {rd }}$ implant under vertical $\&$ oblique load applications as follows:

Under vertical load: Von Misses stresses values were (40.762 Mpa, 26.175 Mpa \& $10.62 \mathrm{Mpa})$ around the 1 st, $2^{\text {nd }} \& 3^{\text {rd }}$ implant respectively. Fig (8)

Under oblique load: Von Misses stresses values were (41.484 Mpa, 28.656 Mpa \& 15.585 Mpa) around the $1^{\text {st }}, 2^{\text {nd }} \& 3^{\text {rd }}$ implant respectively. Fig (9)

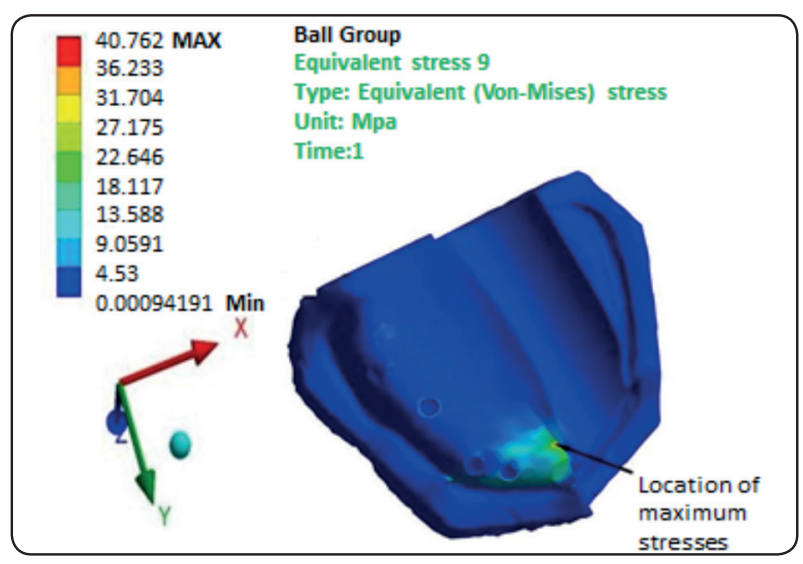

Fig (8) Areas of maximum and minimum stresses under vertical loading (Ball group)

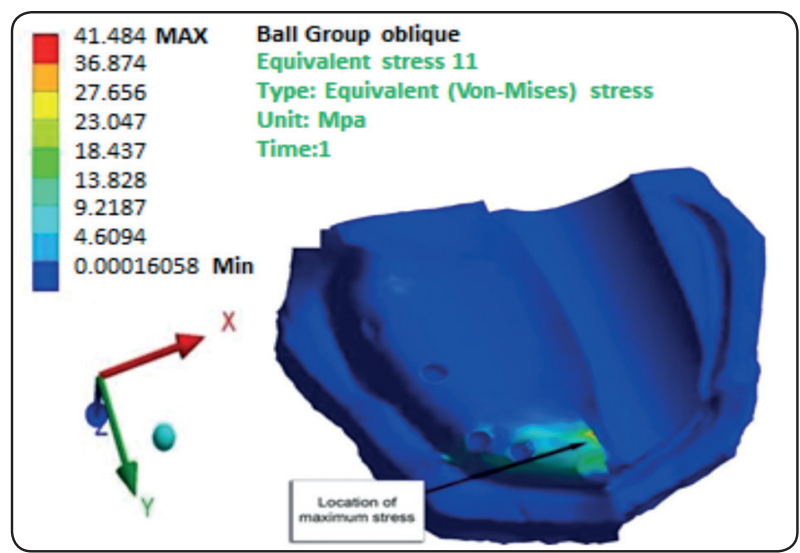

Fig (9) Areas of maximum and minimum stresses under oblique loading (Ball group) 


\section{Results of Model (II): Bar Implant Retained Maxillary Obturator:}

Figure $(10 \& 11)$ is showing that the highest stresses were detected at the mesio- palatal cortical plates around the implant adjacent to the defect, followed by the $2^{\text {nd }} \&$ the $3^{\text {rd }}$ implant.

Under vertical load: Von Misses stresses values were (43.526 Mpa, 29.17 Mpa \& 8.6 Mpa) around the $1^{\text {st }}, 2^{\text {nd }} \& 3^{\text {rd }}$ implants respectively. Fig (10)

Under oblique load: Von Misses stresses values were (53.802 Mpa, 30.5 Mpa \& 9.6 Mpa) around the $1^{\text {st }}, 2^{\text {nd }} \& 3^{\text {rd }}$ implants respectively. Fig (11)

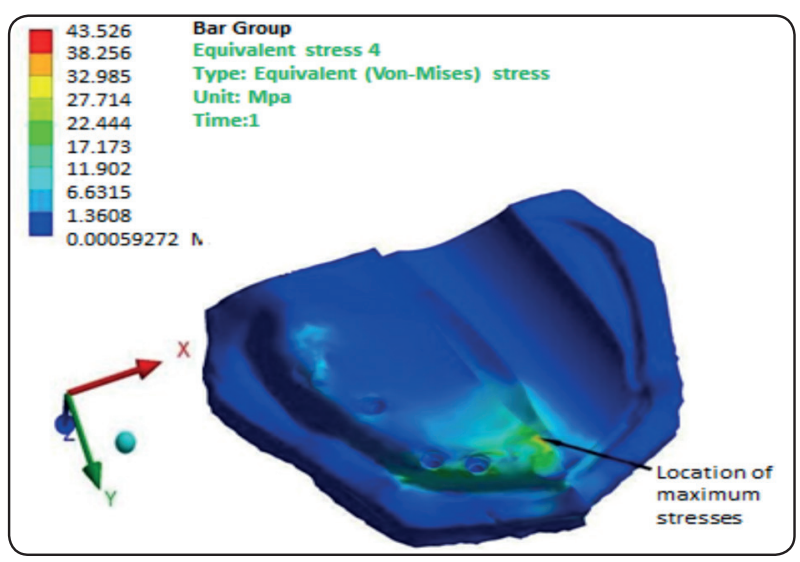

Fig (10) Areas of maximum and minimum stresses under vertical loading (Bar group)

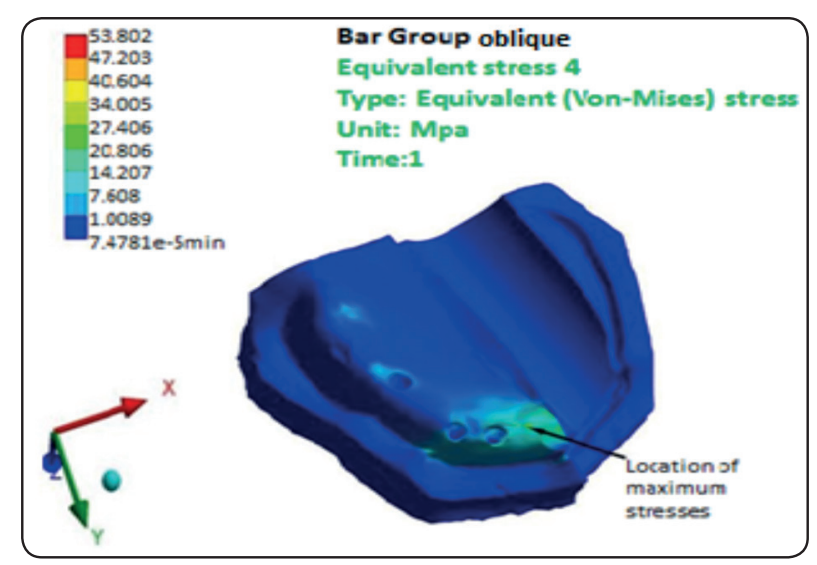

Fig (11) Areas of maximum and minimum stresses under oblique loading (Bar group)

\section{DISCUSSION}

The present study was conducted to evaluate stresses induced in implant retained maxillary obturators whenever they are splinted with custom made bar or solitary implants with ball attachment system. FEA has been applied to predict the stress distribution patterns at the Implant/bone interface in various studies ${ }^{(17,18)}$

Failures of implant-retained prosthesis may be due to excessive stresses that are transmitted to the implants / attachment systems which may lead to fracture of the implant components or induce excessive bone resorption around implants. ${ }^{(19)}$

Bone geometry \& mechanical properties of utilized materials may affect the accuracy of stress distribution patterns to a great extent. ${ }^{(20,21)}$.

In this study, the model was constructed from a CT scanning of a patient with Class I maxillary defect, the model was then designed with computer software, consequently the model was nearly identical to the actual situation of defect and the surrounding maxillary bones. $100 \mathrm{~N}$ was applied as also used in previous studies ${ }^{(16,22)}$

Three implants were distributed along the alveolar ridge to allow better load distribution. ${ }^{(23)}$

The results of this study showed that bar attachment system had recorded the highest Von Misses stresses than un-splinted ball \& socket attachments

These finding may agree with Pesquira et al, ${ }^{(24)}$ who reported that three individualized O-rings provided the lower values of stress in the implants and supporting tissues.

These results also agree with previous study compared different attachment systems used in implant overdentures ${ }^{(25)}$

Moreover, it was reported that better stress distribution in implant overdentures occurs on using unsplinted implants. ${ }^{(26)}$ 
The highest Von Misses stresses detected in the cortical bony layers surrounding the implant necks may be explained by the higher modulus of elasticity of the cortical bone than cancellous bone; which may lead to a limited ability of the compact bone to absorb or dissipate forces delivered onto the implant/bone interface.

Consequently, crestal bone loss occurs around implants on excessive load application. On oblique load application, the load is analyzed into vertical, horizontal \& shears components. Implants are designed to tolerate the vertically applied forces and the implant-prostheses may adapt to compressive forces.

However, the horizontal \& shear force components tend to induce stresses at the implant/ bone interface. Consequently, the highest Von Misses stress values are recorded under oblique load.

These results agree with, Jemt et al.1996 (27) who conclude that the direction of occlusal forces is more influential than the connection of implants.

The highest stresses detected at the implant adjacent to the defect might be due to the magnification of load applied by the long lever arms present after maxillary resection. As reported in previous studies ${ }^{(28,29)}$

The results of Model- I (Ball attachment) are consistent with previous studies as Pesqueira et al.,2013 and Goiato et al., $2012^{(24,30)}$ who concluded that ball attachment transmits less stresses to the implants in implant retained obturators due to the resilient characteristic of the Nylon caps female parts of the ball attachment system that absorb and distribute stresses delivered to them more homogeneously.

The highest Von Misses stresses were noticed in Model -II bar \& clip attachment implant retained obturators. This observation could be explained as follows:
As the obturator is supported from one side by the bar while on the defect area it rests on soft tissue only, which is considered as a cantilever. The presence of cantilevers may increase the forces transmitted to implants, possibly up to 2 or 3 times the applied load on a single implant, due to moments occurs around the placed implants. ${ }^{(31)}$

\section{CONCLUSIONS}

Within the limitations of this study it may be concluded that:

- Ball attachment system may induce the least stresses onto implant/ bone interface.

- Bar retained maxillary obturators result in higher stress concentration around the implants underneath

- Hader bar \& clip attachment may allow better stress distribution in implant retained maxillary obturators than other Bar systems.

- The load direction has more important role than the attachment type in stress distribution pattern in implant retained maxillary obturators.

\section{RECOMMENDATION}

As the results of finite element analysis is only an approximation to the real situation; it is recommended to make further clinical studies to verify the results of this research.

\section{REFERENCES}

1. Cheng Chena Wenhao Rena Ling Gaob Zheng Chengc Linmei Zhanga Shaoming Lia Pro Ke-qian Zhid : Function of obturator prosthesis after maxillectomy and prosthetic obturator rehabilitation Braz. j. otorhinolaryngol. vol.82 no.2 São Paulo Mar./Apr. 2016

2. Kahnberg KE, Nilsson P, Rasmusson L. Le Fort I osteotomy with interpositional bone graft s and implants for rehabilitation of the severely resorbed maxilla: A 2-stage procedure. Int J Oral Maxillofac Implants 1999;14:571-8.

3. Keller EE, Tolman DE, Eckert S. Surgical-prosthodontic reconstruction of advanced maxillary bone compromise with autogenous onlay block bone grafts and osseointegrat- 
ed endosseous implants: A 12-year study of 32 consecutive patients. Int J Oral Maxillofac Implants 1999;14:197-209.

4. Hobkirk J, Watson R, Searson L. Introducing dental implants. Michaelm Parkinson. 1st ed. London: Churchill Livingstone; 2003. pp: 120.

5. Roumanas ED, Nishimura RD, Davis BK, Beumer J. Clinical evaluation of implants retaining edentulous maxillary obturator prostheses. J Prosthet Dent 1997; 77:184e90.

6. Murat S, Gurbuz A, Isayev A, Dokmez B, Cetin U. Enhanced retention of a maxillofacial prosthetic obturator using precision attachments: Two case reports. Eur J Dent 2012; 6:212-7.

7. Keyf F.: Obturator prostheses for hemimaxillectomy patients. J Oral Rehabil. 2001; 28(9): 82.9

8. Leles CR, Leles JL, de Paula Souza C, Martins RR, Mendonça EF. Implant-supported obturator overdenture for extensive maxillary resection patient: A clinical report. J Prosthodont 2010;19:240-4.

9. Monaem AA, Shaker K. Use of osseointegrated implants to retain obturators of edentulous patients. Cairo Dent J 2009;1:8.

10. Parel SM, Brånemark PI, Ohrnell LO, Svensson B. Remote implant anchorage for the rehabilitation of maxillary defects.J Prosthet Dent 2001;86:377-81.

11. Yokoyama S, Wakabayashi N, Shiota M, Ohyama T. The influence of implant location and length on stress distribution for three-unit implant-supported posterior cantilever fixed partial dentures. J Prosthet Dent 2004; 91:234e40.

12. Herekar MG, Patil VN, Mulani SS, Sethi M, Padhye O. The influence of thread geometry on biomechanical load transfer to bone: a finite element analysis comparing two implant thread designs. Dent Res J Isfahan 2014;11:489e94..

13. 1S. Tada, R. Stegaroiu, E. Kitamura, O. Miyakawa, and H. Kusakari, "Influence of implant design and bone quality on stress/strain distribution in bone around implants: a 3-dimensional finite element analysis," International Journal of Oral and Maxillofacial Implants, vol. 18, no. 3, pp. 357-368, 2003.

14. A. M. O'Mahony and J. L. Williams, "Anisotropic elastic properties of cancellous bone from a human edentulous mandible," Clinical Oral Implants Research, vol. 11, pp. 415-421, 2000.

15. Barao VA, Assuncao WG, Tabata LF, Delben JA, Gomes _
EA, de Sousa EA, et al. Finite element analysis to compare complete denture and implant-retained overdentures with different attachment systems. J Craniofacial Surg 2009;20:1066e71

16. Eraslan O, Sevimay M,Usumez A, Eskitascioglu G. Effects of cantilever design and material on stress distribution in fixed partial dentures e a finite element analysis. J Oral Rehab 2005;32:2738.

17. Himmlova L, Dostalova T, Kacovsky A, Konvickova S. Influence of implant length and diameter on stress distribution: a finite element analysis. J Prosthet Dent 2004;91:20e5.

18. Duyck J, Van Oosterwyck H, Vander Sloten J, De Cooman M, Puers R, Naert I. Magnitude and distribution of occlusal forces on oral implants supporting fixed prostheses: an in vivo study. Clin Oral Implants Res 2000;11:465e75.

19. Dilek OC, Tezulas E. A mini implant-supported obturator application in a patient with partial maxillectomy due to tumor: case report. Oral Surg Oral Pathol Oral Radiol Endod 2007; 103:e6e10.

20. Bagis B, Aydogan E, Hasanreisoglu U. Rehabilitation of a congenital palatal defect with a modified technique: a case report. Cases J 2008;1:39.

21. Korkmaz FM, Korkmaz YT, Yalug S, Korkmaz T. Impact of dental and zygomatic implants on stress distribution in maxillary defects: a3-dimensional finite element analysis. J Oral Implantol 2012;38:557e67.

22. Barao VA, Assuncao WG, Tabata LF, Delben JA, Gomes EA, de Sousa EA, et al. Finite element analysis to compare complete denture and implant-retained overdentures with different attachment systems. J Craniofacial Surg 2009;20:1066e71

23. Pesquira AA, Goiato MC, Santos DM, Nobrega AS, Haddad MF, Andreotti AM, et al. Stress analysis in oral obturators prostheses: imaging photoelastic. J Biomed Opt 2013:18.

24. Assuncao WG, Baraeo VA, Tabata LF, De Sousa EA, Gomes EA, Delben JA. Comparison between complete denture and implant-retained overdenture: effect of different mucosa thickness and resiliency on stress distribution. Gerodontology 2009;26:273e81.

25. Kenney R, Richards M. Photoelastic stress patterns produced by implant-retained overdentures. J Prosthet Dent 1998;80:559e64. 
26. Jemt T, Chai J, Harnett Heath MR, Hutton JE, Johns RB. A 5- year prospective multicenter follow-up report on overdentures supported by osseointegrated implants. Int $\mathbf{J}$ Oral Maxillofac Impl 1996;11:291-8.

27. Horshaw SJ, Brunski JB, Cochran G.: Mechanical loading of Branemark implants affects interfacial bone modeling and remodeling. Int J Oral Maxillofac Implants 1994;9:345-60.

28. Roumanas E., Nishimura R., and Beumer J. use of osseointegrated implants in the maxillary resection patient.
In: Proceedings of the 1st International Congress on Maxillofacial Prosthetics. Zlotolow I, Esposito S, Beumer J eds.1995.

29. Goiato M. C. et al., "Photoelastic analysis to compare implant-retained and conventional obturator dentures," J. Biomed. Opt., 17 (6), 061203 (2012).

30. Patterson EA, Burguete RL, Thoi MH, Johns RB. Distribution of load in an oral prosthesis system: an in vitro study. Int J Oral Maxillofac Implants. 1995; 10: 552-60. 